\title{
INSTALACIÓN DE CUBIERTA VEGETAL EN TALUDES DE OBRAS EN ZONAS ÁRIDAS
}

\author{
(INSTALATION OF VEGETATION ON SLOPES PRODUCED BY PUBLIC WORKS \\ IN ARID ZONES)
}

\author{
Juán I. García Viñas. ${ }^{1}$ Carlos Carreras Egaña. ${ }^{2}$ Mariana Orti Moris ${ }^{3}$ \\ ESPAÑA
}

Fecha de recepción: 27 - IV - 93

$113-21$

\section{RESUMEN}

El artículo expone la necesidad de un tratamiento especial de los desmontes $y$ terraplenes realizados en zonas de clima árido $y$ semiárido, con particular referencia al sureste peninsular. Las condiciones extremas de estas áreas, por clima y sustratos, dificultan el borrado de la huella de la actuación humana. En este trabajo se describen las principales dificultades $y$ se sugieren un conjunto de soluciones $y$ tratamientos, así como una selección de especies de fácil propagación e implantación, que permitan una armonía con el paisaje.

\section{SUMMARY}

This article describes the need of an especial treatment for clearan$c e$ and terraced land attained in arid and semi-arid areas with a particular reference to South-East Spain. The extreme conditions of these areas because of the weather and substratum put obstacles in the way of tracing the human action. This paper underlines the main difficulties and suggests some solutions, treatments and a selection of easy propagation species and till that allow keeping armony with landscape.

\section{INTRODUCCIÓN}

El concepto de "zona árida" es de difícil precisión. Este artículo se refiere a todas aquellas en las que el desarrollo vegetativo está muy limitado por falta de disponibilidades hídricas. Las plantas que habitan en estas zonas tienen un marcado carácter xerófilo y forman estructuras vegetales más o menos claras. Las regiones de la Península Ibérica que presentan mayor aridez se corresponden con las zonas más bajas del sur, toda la región del sureste, incluida la depresión del Segura y Guadiana Menor, la parte media inferior del levante y la depresión del Ebro.

\footnotetext{
1 Botánica, E.U.I.T. Forestal. Universidad Politécnica de Madrid.

2 Dto. Actuaciones Forestales, Delegación de Agricultura. Almeria.

3 Botánica. E.T.S.I. Montes, Universidad Politécnica de Madrid.
}

En las zonas de climas benignos, con abundantes precipitaciones y temperaturas suaves, la colonización de los taludes es razonablemente fácil. Cuando las condiciones climáticas son adversas y especialmente lo son cuando la falta de agua es extrema, la colonización natural o la dirigida por el hombre es muy lenta. Se pueden citar muchos ejemplos de taludes de carreteras de zonas áridas en los que después de más de cinco años apenas han sido colonizados por una vegetación incipiente y esporádica. También hay ejemplos de taludes en zonas áridas tratados sin éxito, en gran medida por una secuencia de episodios climáticos extremadamente desfavorables. Además frecuentemente existe una dificultad añadida como es la presencia de sustratos de características especiales que contribuyen a dificultar_más la instalación de una cubierta vegetal. A pesar de todos estos inconvenientes, los taludes de estas áreas se pueden 
tratar y quedar integrados en el paisaje. Una cuidadosa elección de las especies a utilizar, una combinación de técnicas o la simple plantación y tratamiento posterior son la forma de garantizar, a nuestro juicio, el éxito. La superación de estas dificultades supone en términos económicos un mayor costo.

\section{CARACTERÍSTICAS DE LAS ZONAS ÁRIDAS}

Los principales factores y características que pueden limitar o dificultar la consecución de una cubierta vegetal en taludes pueden resumirse en los siguientes puntos:

\subsection{Aspectos desfavorables que presenta el clima:}

- La escasez de precipitaciones. Al ser mucho menores que la evapotranspiración, la actividad vegetativa potencial queda fuertemente limitada y por consiguiente el crecimiento de las plantas es muy lento, lo que se traduce en que la densidad o el espesor de la cubierta vegetal sea generalmente muy reducido (la acumulación de biomasa requiere períodos de tiempo muy prolongados).

- Irregularidad climática. La elevada frecuencia de años con precipitaciones muy escasas supone altas mortalidades en las plantas recién aparecidas y el debilitamiento de las ya instaladas.

- Torrencialidad de las precipitaciones. Es una faceta más de la irregularidad climática, que destacamos porque es la responsable de la producción de fuertes escorrentías y, por tanto, de fuertes erosiones y deposiciones de lodo, que entre otros daños afectan también a la vegetación incipiente, produciendo su descalce o su arrastre o bien anegando su parte aérea.

- Elevadas evapotranspiraciones. Afectan a la economía hídrica de la vegetación, ya apuntadas. Pueden variar considerablemente en función de la insolación (máxima en laderas con orientación de S-SO) y la exposición al viento.

\subsection{Aspectos desfavorables de los sustratos:}

- Presencia de arcillas o de minerales hinchables. Además de suponer una escasa permeabilidad (e infiltración), suele dar lugar a coladas de barro, deslizamientos, etc. En el período estival estos sustratos experimentan grietas de retracción, especialmente cuando se presentan desnudos, que dificultan la instalación de determinadas plantas.

- Compacidad. Se presenta este problema en el caso de desmontes en rocas duras y poco fisuradas o de margas compactas. Afecta a las plantas en dos aspectos fundamentales: en el desarrollo del sistema radical que queda limitado por la impenetrabilidad o por falta de aireación, y por otra parte en la capacidad del sustrato de retener agua a disposición de las plantas, que depende de su porosidad, que es también reducida. Puede señalarse, además, que la infiltración del agua se ve también dificultada o impedida por esta causa.

- Tamaño de los elementos. La presencia de elementos de tamaño grueso en superficie impide o dificulta la instalación de nuevas plántulas, que requieren tierra fina para poder germinar y arraigar.

- Falta de microorganismos simbiontes. En taludes de desmonte o en terraplenes totalmente desprovistos de tierra vegetal pueden faltar o ser insuficientes los microorganismos que establecen relaciones simbióticas con las plantas que se quieren introducir, como hongos micorrizógenos, o bacterias fijadoras de nitrógeno en las raíces.

- Salinidad. Supone una cierta toxicidad o problemas en la absorción de nutrientes, además de una mayor presión osmótica de la solución del suelo, en prejuicio de la economía hídrica de las plantas. Se presenta frecuentemente en margas miocénicas y en algunos terrenos cuaternarios del valle del Ebro y sureste peninsular. Por acción de la escorrentía superficial pueden contaminar otros sustratos próximos.

- Los yesos también son frecuentes, se pueden presentar en masa o formando capas más o menos abundantes. Se comportan como una sal débil y suponen toxicidad y dificultades en la absorción de agua. Las especies utilizables quedan muy restringidas por la presencia del sulfato y hay que recurrir a plantas gipsófilas.

\subsection{Características topográficas del talud:}

- Pendiente. A mayor pendiente del talud encontramos menor estabilidad del sustrato y de los propágulos que puedan estar instalados en él. También supone menor disponibilidad de agua (menor recepción de agua de lluvia y mayor proporción de pérdidas por escorrentía) y menor accesibilidad (dificultad de los trabajos de plantación). 
Foto 1. Daños en una carretera de Almería. Los terraplenes de filitas sin cubierta vegetal son fácilmente erosionables si no tienen una cubierta vegetal.
- La longitud de pendiente. Para la misma pendiente, a mayor longitud, mayor nivel de erosión.

\subsection{Aspectos de la dinámica vegetal:}

En las zonas áridas el dinamismo vegetal está muy atenuado. La progresión vegetal se manifiesta como un proceso discreto que necesita de una secuencia de años de precipitaciones favorables. En los años más secos la evolución vegetal está paralizada y si el carácter de la sequía se extrema pueden llegar a manifestarse retrocesos. Algunas especies mantienen viables sus semillas largo tiempo procediendo a su germinación de forma escalonada (a veces más de 10 años). Otras especies producen grandes cantidades de semillas todos los años que mantienen la viabilidad durante poco tiempo con la esperanza de aprovechar un posible año húmedo. Los taludes y desmontes constituyen un sistema artificial donde la colonización es aún más difícil. Para simular este proceso es necesario realizar el aporte de semillas e imitar las condiciones de un año menos seco mediante riego.

(c) Consejo Superior de Investigaciones Científicas Licencia Creative Commons 3.0 España (by-nc)

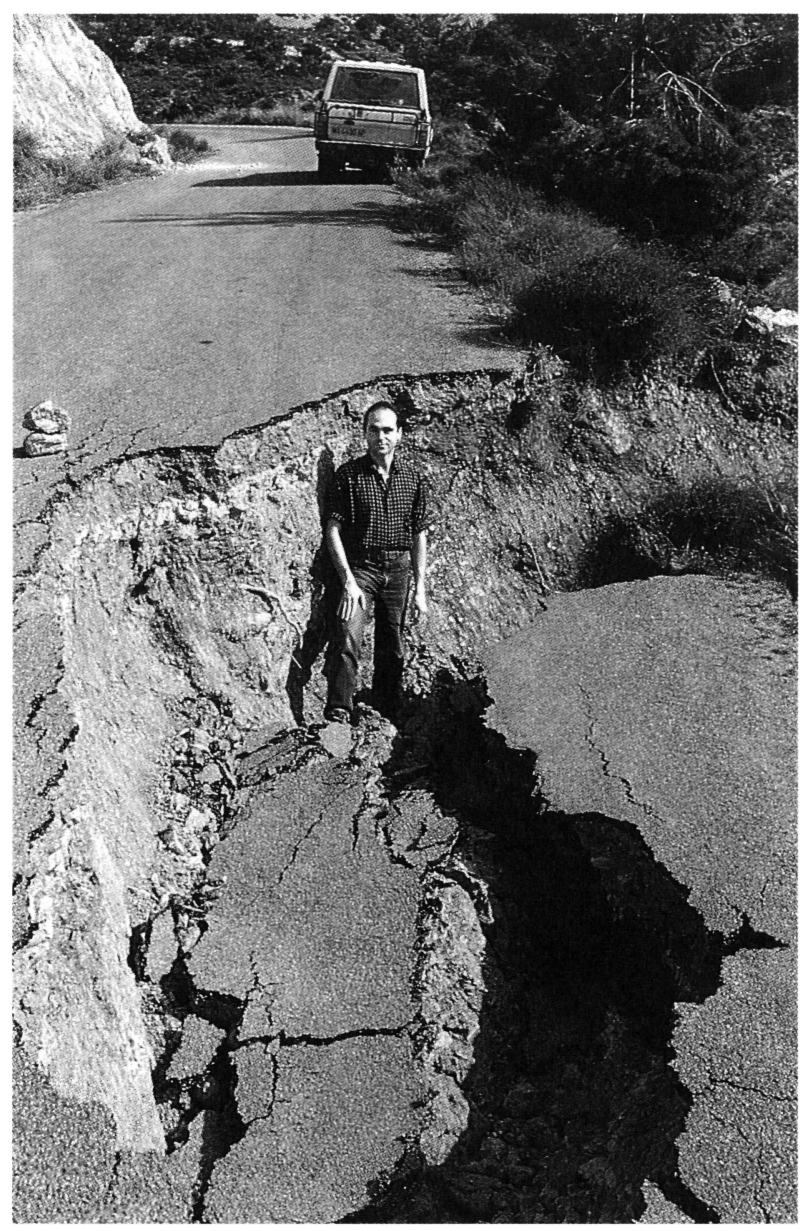

\section{TÉCNICAS DE IMPLANTACIÓN}

\subsection{Consideraciones previas.}

La solución de instalación de cubiertas vegetales en los taludes de desmonte y terraplén, originados por los grandes movimientos de tierras de las obras, parte de la base de la estabilidad mecánica del talud, y por supuesto de la existencia de un sustrato no muy compacto que impida la penetración de las raíces.

Son necesarias las remodelaciones del terreno en los casos siguientes: pendiente excesiva, alteraciones puntuales donde fuera preciso un refuerzo especial y finalmente son también necesarios sistemas de drenajes, bajantes, cunetas, etc, que favorezca la infiltración y disminuya la capacidad erosiva del agua de lluvia en el talud.

Una vez aseguradas las constantes básicas del talud se debe proceder a la implantación de una cubierta vegetal que proporcione una mayor estabilidad al terreno, mejore la estructura del suelo, favorezca la reducción de la erosión hídrica y suponga una inte- 


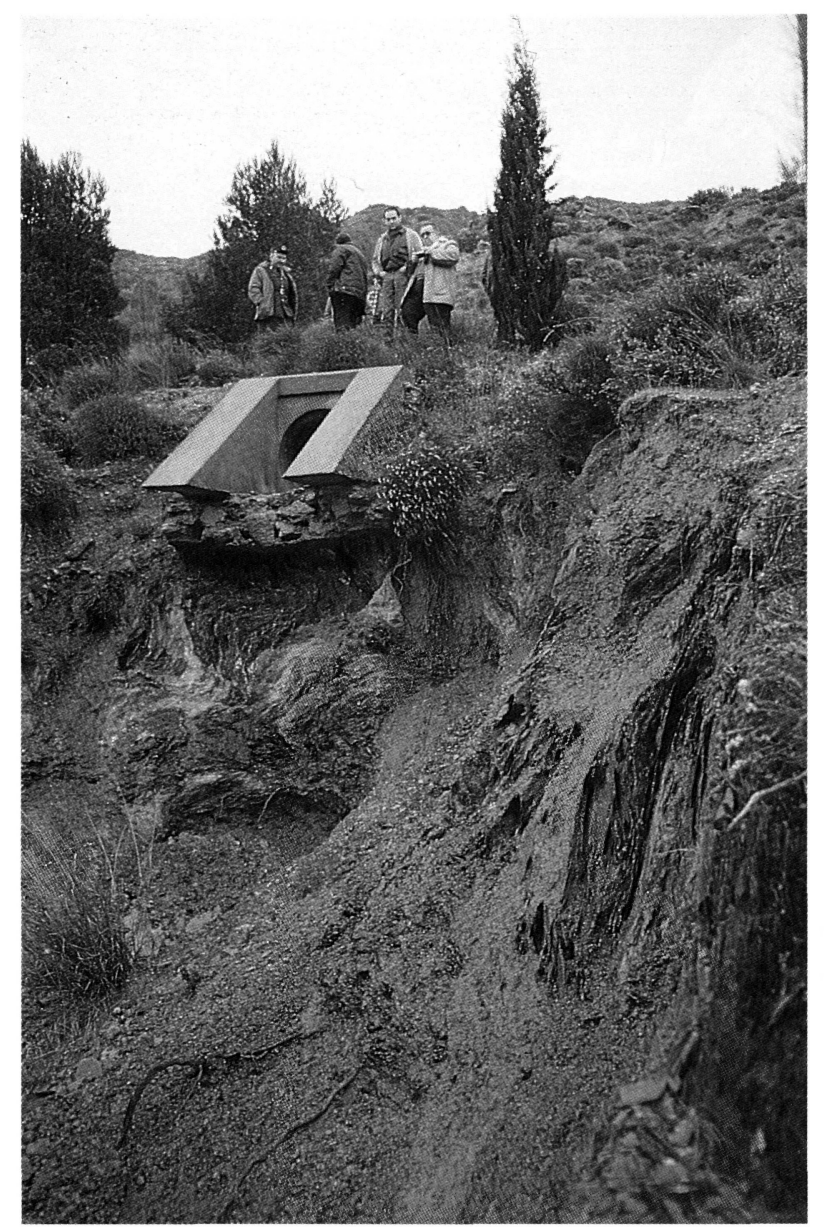

gración de los terrenos afectados en el paisaje, minimizando así el impacto visual producido. En estos taludes, que están afectados por un clima árido, con pendientes considerables y con los inconvenientes citados en el apartado anterior, se torna muy difícil la colonización natural por lo que se hace necesaria la implantación artificial de la vegetación.

\subsection{Tratamiento de los taludes.}

Las técnicas más apropiadas para la implantación de las especies vegetales elegidas para este tipo de zonas son la plantación y la hidrosiembra combinadas de forma que se complementen, o la plantación cuando las especies a emplear y los costos de la siembra lo hagan necesario.

La siembra tiene la ventaja de producir una cubierta de aspecto continuo. La plantación proporciona una rápida reconstrucción del paisaje e integración en los alrededores. En muchos casos el costo del acopio de semillas para la hidrosiembra puede superar de forma exagerada al de la plantación. En la actualidad no es
Foto 2. Deslizamiento del terraplén de filitas en una carretera de la provincia de Almería. Este sustratn limoso, algo salino, capaz de fluir en coladas, requiere un tratamiento con A.thyllis cytisoides.

fácil la obtención de semillas de especies apropiadas para zonas áridas y si se encuentran suelen estar a precios muy altos por el carácter artesanal de su recolección. Por último advertir que los movimientos de los operarios en las plantaciones en taludes de sustratos blandos como yesos, algunas margas salinas o filitas, pueden ocasionar grandes destrozos y ser recomendada en estos casos la hidrosiembra.

El diseño de la plantación debe hacerse imitando, en lo posible, el paisaje circundante. En la mayoría de los casos hay que evitar las disposiciones regulares y continuas, las cuales mantienen la misma distancia entre individuos, repiten las combinaciones de especies uniformemente y tienen límites bruscos y lineales. Se propone hacer bosquetes o núcleos de colonización irregulares, mezclando especies de forma similar al paisaje natural cercano y tratando de localizarlos en zonas donde el pisoteo de los operarios efectúe el menor daño posible.

En algunos casos podrá recurrirse a plantaciones regulares y de poca diversidad, como por ejemplo 
cuando queramos recrear un espartal (agregado dominado por Stipa tenacissima), un albaidar (agr. dominado por Anthyllis cytisoides), determinados romerales, etc.

Las especies de zonas áridas suelen tener elevada relación parte radical/p. aérea. Para atenuar las severas condiciones de sequía tienen, generalmente, unos sistemas radicales voluminosos y profundos con los que extraer agua de las partes más profundas del sustrato. Las plantas deberán ser producidas en envases grandes a fin de poder conseguir un buen desarrollo del sistema radical. Son especialmente recomendados los envases de $300 \mathrm{~cm}^{3}$ de volumen y $18 \mathrm{~cm}$ de longitud, como los conocidos Forest-Pot. Los envases pequeños, como los de 150 $\mathrm{cm}^{3}$ y $12 \mathrm{~cm}$ de longitud, no permiten el desarrollo de sistemas radicales suficientemente profundos ni la cantidad necesaria.

Las dimensiones del hoyo de plantación se fijarán según el tamaño del cepellón, el cual debe permitir soportar veranos largos y secos así como evitar el enrollamiento de las raíces laterales.

La densidad de plantación se realizará con un espaciamiento variable según el diseño, pero que puede oscilar entre unos 3 ó $6 \mathrm{~m}$ para las especies que puedan alcanzar talla arbórea, de 2 a $4 \mathrm{~m}$ para los arbustos y matas altas y de 1 a $2 \mathrm{~m}$ o incluso menos de $1 \mathrm{~m}$ para las matas y herbáceas vivaces. Estos valores deberán ser ajustados en función del desarrollo esperado de la parte aérea, el tipo de sistema radical y de la densidad que observemos en las cubiertas vegetales semejantes de las zonas próximas.

La época más idónea para la plantación, salvo excepciones, es el otoño, temporada en la que se registra el máximo de precipitación en estas zonas. Se pretende que las plantas tengan el mayor tiempo posible para el desarrollo radical en el talud y así poder afrontar mejor la sequía y las altas temperaturas estivales.

Se recomienda el trasplante vivero-campo, pasándose las plantas generalmente con dos o tres savias. La procedencia es deseable que sea de viveros próximos o que soporten condiciones climatológicas similares a las de la zona a tratar. En los casos de tratamiento de taludes de sustratos salinos o yesosos es importante que la tierra de los envases sea de características semejantes. También es recomendable el empleo en el sustrato del envase de polímeros superabsorbentes tipo "Aguaspón ”.
Como anteriormente se ha dicho, en estas zonas hay una elevada irregularidad de las precipitaciones, tanto cualitativa como cuantitativa. La plantación se asentará si el primer año es pluvimétricamente favorable. Si, por el contrario, el otoño y la primavera son especialmente secos o el verano excesivamente prolongado y caluroso, las plantas tienen demasiadas posibilidades de perecer. Por estas razones se consideran necesarios los riegos, sobre todo cuando la sequía amenace de forma que exista el riesgo de pérdida de la mayoría de las plantas. Las cantidades de agua por plantas son muy variables y dependen de muchos factores pudiendo cifrarse de forma orientativa entre 2 y 6 litros por planta y riego, de cuatro a seis veces en junio, agosto y septiembre y seis a ocho veces en julio.

En algunos casos las plantaciones deberán protegerse del ataque de los pequeños herbívoros (conejos y liebres causan con frecuencia daños importantes).

Combinada con la plantación es necesario realizar hidrosiembra. Las principales razones por las que se propone utilizar esta técnica, como ya se ha dicho, son las de obtener un tratamiento continuo y poder tratar estas zonas sin acceder a ellas, lo cual evita posibles riesgos en estos taludes tan fácilmente erosionables. Además, la utilización de " mulch " favorece la retención de agua, disminuye la evaporación y la temperatura del suelo y proporciona un aporte de materia orgánica y protege a las semillas de la predación por aves granívoras; y finalmente la de la utilización de sustancias estabilizadoras que fijan los productos al suelo. Se propone efectuar la hidrosiembra después de la plantación, si ambas técnicas se combinasen sobre los espacios libres dejados por ésta.

La cantidad de disemínulos a utilizar depende del poder germinativo y del tamaño de cada tipo, de la naturaleza de las especies que compongan la mezcla, de la tasa de pervivencia, de la pendiente del talud, etc.

Los tratamientos previos de las semillas son recomendables, teniendo en cuenta que se van a efectuar una serie de riegos que no sólo favorecen la germinación, sino que asegurarán la supervivencia de la plántula recién nacida. Se propone para la mayor parte de las especies de leguminosas un tratamiento de inmersión en agua caliente a $80^{\circ} \mathrm{C}$ durante medio minuto y un remojo en el mismo agua hasta temperatura ambiente durante 24 horas.

El revestimiento de los taludes debe ser tupido. Para ello se efectúa una segunda fase de tapado que ase- 


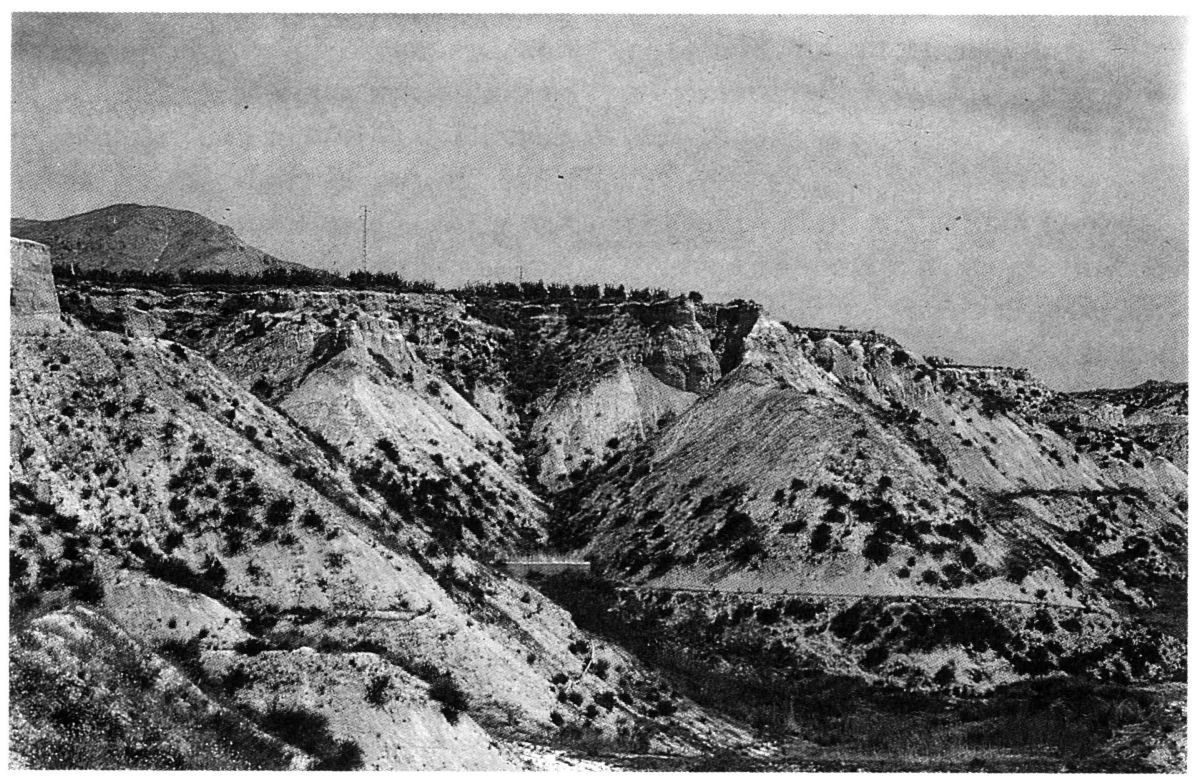

Foto 3. Margas miocénicas salinas. El tratamiento de taludes sobre estos sustratos salinos requiere el empleo de especies haloxerófilas como Salsola genistoides $y$ Atriplex glauca.

gure una protección muy completa de las semillas frente a la evaporación y las altas temperaturas, gracias a la formación de un microclima favorable y una buena protección frente a la acción de granívoros. En esta última fase se deben incluir las semillas de especies que tienen una emergencia más delicada como por ejemplo Salsola genistoides.

La época más idónea para efectuar la hidrosiembra, al igual que ocurre para la plantación, es en otoño (salvo excepciones), por las mismas razones ya antes apuntadas.

Se recomienda proporcionar varios riegos (más de dos por cada mes seco), sobre todo teniendo en cuenta que las semillas utilizadas han sufrido tratamientos que favorecen la germinación y un retraso en los aportes de agua puede suponer la muerte de la mayoría de las plántulas aparecidas.

Por último recordar la importancia de guardar y posteriormente utilizar el suelo que quitemos en la ejecución de la obra. Aunque esta operación representa un costo más, se considera muy importante. Recordemos que este sustrato representa una fracción alterada de la roca, aportando mejores condiciones para el desarrollo vegetal y, lo que es más importante, capitaliza una cantidad grande de semillas de especies del lugar, capaces de germinar cuando las condiciones sean favorables y contribuir a la colonización del talud.

(c) Consejo Superior de Investigaciones Científicas

\section{SELECCIÓN DE ESPECIES}

\subsection{Criterios de selección.}

No se pretende la reproducción de las comunidades vegetales presentes en el entorno sino la instalación de una cubierta de especies que estén en armonía con el paisaje en estructura y composición florística.

Las especies deben de ofrecer unas facilidades de reproducción y de obtención de disemínulos que las hagan atractivas. Frugales y de bajo mantenimiento, en el sentido relativo de su entorno, con sistemas radicales aptos a las condiciones del talud. Los crecimientos deben de ser al menos moderadamente rápidos.

Teniendo en cuenta las consideraciones antes expuestas y la flora de las zonas áridas peninsulares, especialmente de las especies dominantes y colonizadoras, exponemos el siguiente catálogo de especies por grupos de tamaño:

- Especies que pueden alcanzar la talla arbórea:

Pinus halepensis Miller.

Como elemento del paisaje de eoníferas xerófilas del sureste y valle del Ebro. Puede emplearse en siembra y plantación. 


\section{Elaeagnus angustifolia $\mathrm{L}$.}

Para zonas de sustratos salinos o yesosos, en situaciones en las que pueda recibir un aporte hídrico extraordinario como proximidades de drenajes, alcantarillas, etc. Empleada en plantación o estaquillado directo en talud.

\section{Phoenix dactylifera $\mathrm{L}$.}

Especie integrada en el paisaje de cauces y ramblas del sureste y levante. Resistente a sustratos con un cierto contenido en sales. En zonas con aporte hídrico extraordinario. Siembra y plantación.

\section{Tetraclinis articulata (Vahl) Masters.}

En taludes orientados y próximos al mar y sin contenido de sales ni yeso. Plantación.

- De talla arbustiva:

Tamarix africana Poiret, Tamarix canariensis Willd, Tamarix gallica L.

Para zonas con aporte extraordinario de agua, como partes bajas de desmontes y terraplenes, proximidades de alcantarillas, etc. Plantación.

Vitex agnus-castus $\mathrm{L}$.

Caducifolio de carácter termófilo. En zonas de aporte hídrico extraordinario. Plantación.

- De talla de mata:

\section{Ephedra fragilis Desf.}

Como componente de recreaciones de matorral pluriespecífico. Poco resistente a sustratos salinos o yesosos. Preferiblemente por plantación.

\section{Ephedra nebrodensis Tineo ex Guss.}

De utilización semejante a la anterior, pero apropiada para sustrato con yeso.

\section{Anabasis articulata (Foskal) Moq.}

Presenta una fructificación muy vistosa. Idónea para zonas termófilas y con sustrato salino, en todo tipo de pendientes y exposiciones. Siembra seguida de riegos o plantación.

Anthyllis cytisoides L.

De profusa floración amarilla. Para sustratos algo arenosos y limosos, tolerando un cierto grado de sales. Apropiada para todo el sureste, especialmente en exposiciones de umbría. Siembra seguida de riegos o plantación.
Anthyllis terniflora (Lag.) Pau.

Flores amarillas. De utilización semejante a la anterior pero más termófila.

\section{Atriplex glauca $\mathrm{L}$.}

Forma matas paqueñas y densas. Muy frugal. Utilizable sobre margas salinas, en todas las pendientes y exposiones. Tolera el frío. Siembra y plantación.

\section{Atriplex halimus L.}

De mayor talla que la especie anterior. Para alcanzar sus mejores desarrollos es necesaria su colocación en las partes medias y bajas. Siembra y plantación.

\section{Chamaerops humilis $\mathrm{L}$.}

Como elemento de recreación de los paisajes costeros mediterráneos. Plantación.

Coridothymus capitatus (L.) Reichenbach fil.

De floración tardía (junio). Como elemento de recreación de las formaciones monoespecíficas de tomillares costeros mediterráneos. Sustratos preferentemente calizos. Siembra y plantación.

\section{Coronilla juncea $\mathrm{L}$.}

De floración vistosa. Se desarrolla mejor en zonas con un cierto aporte hídrico extraordinario (taludes, proximidades a cunetas o alcantarillas, etc. ). Siembra o plantación.

\section{Franquenia corimbosa Desf.}

Flores blancas, profusas. Apropiada para sustratos salinos próximos a la costa. Se puede emplear formando rodales monoespecíficos. Plantación.

Franquenia thymifolia (L.) Spach ex Webb. Para sustratos con presencia de sales en zonas con una cierta continentalidad. Plantación

\section{Genista ramossisima (Desf.) Poiret}

De floración exuberante. Idónea para zonas termófilas en todos los sustratos, especialmente resistente a los yesosos. Siembra y plantación. (Foto 4).

\section{Genista spartioides Spach}

En zonas próximas a la costa, en sustratos calizos y silíceos. Como elemento en recreaciones de matorrales pluriespecíficos, termófilos. Siembra y plantación. 


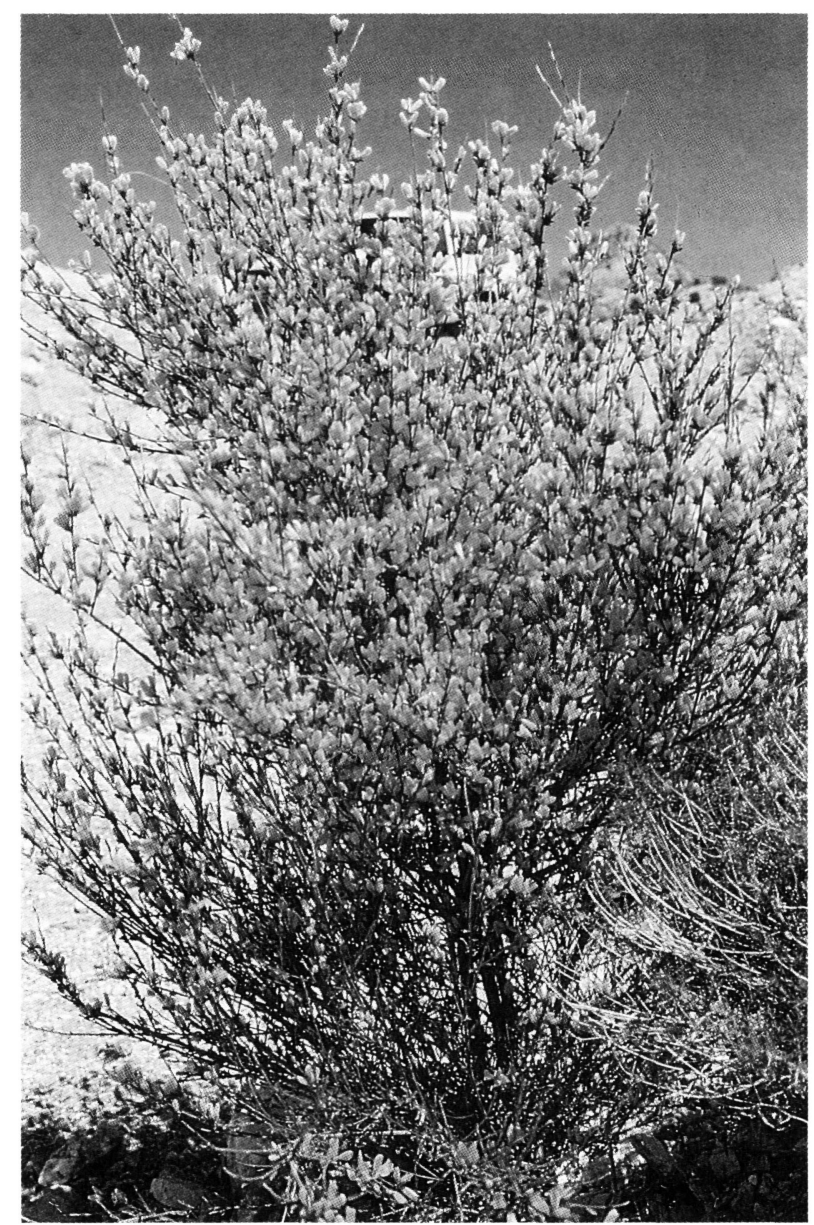

Genista umbellata Poret

Sobre sustratos silíceos, preferentemente esquistosos. Se puede emplear en plantaciones monoespecíficas como recreación de matorrales de dicha especie. Siembra y plantación.

\section{Lavandula dentata $\mathrm{L}$.}

En zonas sin heladas o muy escasas, sobre sustratos calizos o silíceos. Se puede emplear como componente de plantaciones pluriespecíficas y formando rodales. Plantación.

\section{Nerium oleander L.}

En zonas cóncavas o donde se aprecie la posibilidad de un aporte hídrico extraordinario. Plantación. Muy conocida y utilizada.

Periploca laevigata Aiton ssp. angustifolia Markgraf De flores pequeñas de gran belleza. Especie caducifolia. Para zonas costeras, en sustratos calizos y silíceos. Plantación.

\section{Phlomis purpurea L.}

Flores rosa. Para zonas de clima suave, con pocas (c) Consejo Superior de Investigaciones Científicas Licencia Creative Commons 3.0 España (by-nc)
Foto 4. Ejemplar de Genista ramosissima. Especie interesante para taludes sobre sustrato yesoso.

y débiles heladas, formando rodales. Plantación.

Quercus coccifera $\mathrm{L}$.

Como elemento de recreación de paisajes áridos. Plantación.

\section{Retama sphaerocarpa (L.) Boiss.}

Para zonas continentales y de influencia marítima, en sustratos calizos y silíceos. Vegeta mal en salinos y yesosos. Siembra y plantación.

\section{Rosmarinus officinalis L.}

En zonas de clima costero o continental, sobre sustratos calizos o silíceos. Vegeta mal con presencia de sales o yeso. Plantación.

\section{Salsola genistoides Juss. ex Poiret}

De fructificación temprana y vistosa. Para zonas con pocas heladas. Para sustratos margosos salinos. Siembra y plantación.

Thymus baeticus Boiss. ex Lacaita -

Flores blancas. Para zonas con pocas heladas, en sustratos calizos o silíceos. Siembra y plantación. 


\section{Thymus byemalis Lange}

Flores rosa-púrpura. De floración temprana (diciembre a enero). Siembra y plantación.

\section{Capparis spinosa $\mathrm{L}$.}

Flores blancas. Especie extraordinariamente resistente a condiciones de aridez. Sobre todo tipo de sustratos, especialmente los salinos. Plantación.

\section{- Herbáceas}

\section{Hyparrbenia birta (L.) Stapf}

Hemicriptófito muy resistente a la aridez. Especie termófila, sobre sustratos calizos y silíceos no muy salinos. Siembra y plantación.

\section{Lygeum spartum $\mathrm{L}$.}

Gramínea perenne. Resistente a los sustratos salinos y yesosos. No se recomienda su utilización en hidrosiembra por el tamaño de su disemínulo.

\section{- Plantación.}

Stipa capensis Thumb.

Gramínea anual, apropiada para una primera colonización. Especie termófila, sobre sustratos calizos y silíceos. Siembra.

\section{Stipa tenacissima $\mathrm{L}$.}

Gramínea perenne. Para todos los sustratos incluidos los salinos y yesosos. Plantación.

\section{BIBLIOGRAFÍA}

ESTEVE, M. A.; FERRER, D. et alt (1990): Restauración de la vegetación en ecosistemas áridos: algunas reflexiones ecológicas. Ecología. Fuera de Serie $\mathrm{N}^{\circ}$ 1. pp 497-510. ICONA. Madrid.

BRAUN BLANQUET, J.; de BOLOS, O. (1987): Las Comunidades Vegetales de la Depresión del Ebro y su dinamismo. Delegación de Medio Ambiente. Ayuntamiento de Zaragoza.

ORIVE, L.A.; PIÑEDO GONZALEZ, A. (1986): Medidas Estructurales para la Estabilización de Taludes. Curso Monográfico sobre restauración del paisaje. Fundación
Conde Valle de Salazar. Escuela Técnica Superior de Ingenieros de Montes. Madrid.

RAMOS, F. et alt. (1974) Tratamiento Funcional y Paisajístico de Taludes Artificiales. ICONA. Ministerio de Agricultura. Madrid.

RUIZ de la TORRE, J. et alt. (1990). Catálogo de Especies Vegetales a Utilizar en Plantaciones de Carreteras

RUIZ de la TORRE, J. et alt. (1990): Mapa Forestal de España, Hojas: 7-4 Zaragoza, 6-10 Baza y 6-11 Almería. ICONA, Ministerio de Agricultura, Madrid. 